\title{
FUTBOLDA TAKTİK
}

Doç. Dr. Mehmet KOÇAK 


\title{
(C) Copyright 2021
}

Bu kitabın, basım, yayın ve satış hakları Akademisyen Kitabevi A.Ş.'ne aittir. Anılan kuruluşun izni alınmadan kitabın tümü ya da bölümleri mekanik, elektronik, fotokopi, manyetik kağıt ve/veya başka yöntemlerle çoğaltılamaz, basılamaz, dağıtılamaz. Tablo, şekil ve grafikler izin alınmadan, ticari amaçh kullanılamaz. Bu kitap T.C. Kültür Bakanlığı bandrolü ile satılmaktadır.

\section{ISBN}

978-625-7451-81-9

\section{Kitap Adı}

Futbolda Taktik

Yazar

Doç. Dr. Mehmet KOÇAK

\section{Yayın Koordinatörï}

Yasin DİLMEN

\author{
Sayfa ve Kapak Tasarımı \\ Akademisyen Dizgi Ünitesi
}

\section{Yayıncı Sertifika No}

47518

\section{Baskı ve Cilt}

Vadi Matbaacilık

Bisac Code

SPO015000

DOI

10.37609/akya.699

\section{GENEL DAĞITIM}

\section{Akademisyen Kitabevi A.Ş.}

Halk Sokak 5 / A

Yenişehir / Ankara

Tel: 03124311633

siparis@akademisyen.com 


\section{IÇiNDEKILER}

Giriş

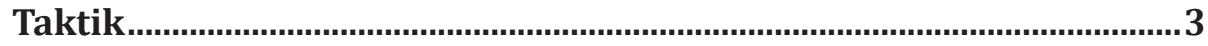

1.1. Taktiğin Şematik Görünümü ve Sınıflandırılması .................................. 4

1.1.1. Bireysel Taktik................................................................................ 4

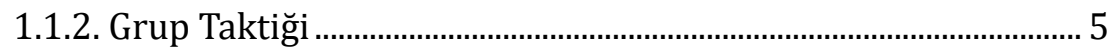

1.1.3. Takım Taktiği....................................................................................... 6

Taktik Oyun Pozisyonu Antrenmanında Beş Temel Basamak............. 11

2.1. Taktik Antrenmanın Dairesel Akışı...........................................................11

2.2. Taktik Antrenmanın Dairesel Akışının Şematik Görünümü .............12

2.3. Gençlerde Grup Taktik ve Birlikte Müdafaa Yapmak ..........................13

2.4. İkili Müdafaa İçin Önemli Öneriler ve Çalışmaları ................................14

2.1.1. Grup Taktik Antrenman İçin Organizasyon Formları ...............29

2.1.2. Grup Taktik Antrenman İçin Organizasyon Formları................35

2.1.3. Süratli Ek Hareket ile 2:1 veya 2:2 Oyun.....................................41

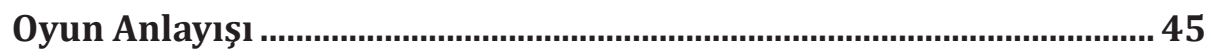

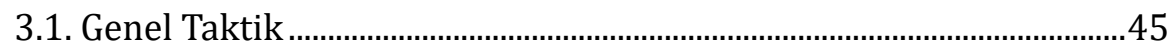

3.1.1. Bireysel ve Pozisyon Taktikleri .................................................45

3.1.2. Bireysel Taktiğin Tanımı............................................................... 45

3.1.3. Pozisyona Yönelik Taktiğin Tanımı..............................................45

3.2. Genel Taktik Ana İlkeleri .........................................................................45

Müsabaka Başarısı İçin Gerekli Faktörler.............................................. 47 
Sahanın Bölgelerinde Yapılması Gerekli Tedbirler................................ 49

5.1. Müdafaa Bölgesi (1. Bölge) ......................................................................49

5.2. Hazırlık Bölgesi (2. Bölge) …………………………...........................50

5.3. Hücum Bölgesi (3. Bölge) …………………………………………….....50

Oyun Bölgeleri ve Taktik Hedefler.......................................................... 51

Topsuz Oyun ve Boș Alana Koșunun Önemi ve Anlamı ......................... 53

7.1. Pas ver Boş Alana Koşuda Önemli Özellikler

(Rakibin Gölge Markajından Doğru Boş Alana Çlk) ............................54

7.2. Pas ver Boş Alana Koşu da Antrenman İçin Özel Öğrenme Amaçları... 55

7.3. Pas Ver Boş Alana Koşu ile İlgili Antrenman Formları .........................56

7.1.1. Hücumda Grup Taktik; Pas Ver ve Boş Alana Koşu ile İlgili Bir Antrenman İçeriği

7.1.2. Pas Ver Boş Alana Koşu İçin Küçük Alıştırma Formları...........66

7.1.3. Topsuz Oyun ve Boş Alana Koşu Çalışmaları

Futbol Metoduna Uygun Olarak Oyuna Yönelik Antrenman ......................83

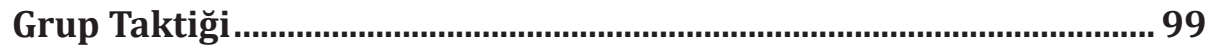

9.1. Müdafaa Taktikleri....................................................................................99

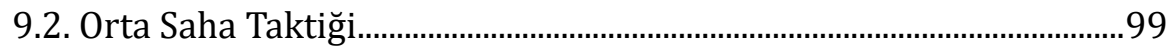

9.3. Forvet Uç Oyuncuları Taktiği .................................................................99

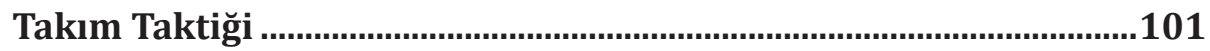

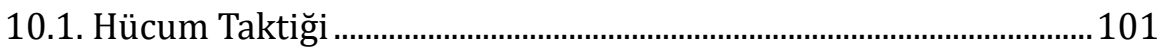

10.2. Müdafaa Taktiği .................................................................................... 101

Özel Taktik .............................................................................................103

11.1. Maç Gününün Koşulları (Dış Koşullar) .............................................103

11.2. Rakip Takım Oyuncuları ve Becerileri ..................................................103

11.3. Maçın Durumu .........................................................................................103

11.4. Standart Durumlar (Serbest Vuruşlar).............................................103

Taktik Düşünme Yeteneği Nasıl Kazandırılır Veya

Taktik Düşünme Yeteneği Nasıl Geliştirilir..........................................105

Adam Markajı Eğitimi ve Çalışmaları......................................................107 
Kayarak Markaj 113

14.1. Kayarak Markaj Çalışmaları

Grup - Takım Taktiği Eğitimi ve Çalışmaları 123

Saha Markajı Eğitimi 131

16.1. Başarılı Bir Saha Markajı İçin Gerekli Şartlar 132

16.2. Saha Markajı Eğitimi Çalışmaları 133

Müdafaaya Yönelik Saha Markajı Eğitimi 153

17.1. Adam ve Saha Markajının Karşılaştırılması 159

17.2. Kombine Markaj 159

Sistem ve Tanımı 161

18.1. Oyun Sistemlerinin Tarihsel Gelişimi. 161

18.2. Oyun Sistemlerinin Gelişimi - Müdafaa ve Hücum Davranışı İçin Anlamı. 162

18.3. WM - Sistemi 162

18.4. Günümüzde Hücuma Yönelik Futbol.....................................................163

18.5. Modern Oyun Sistemleri.................................................................163

18.6. Modern Oyun Sistemleri (Ayrıntılı Olarak) ....................................173

18.6.1. (3-4-3) Oyun Sistemi (Üçlü Zincir Sistemi)...........................174

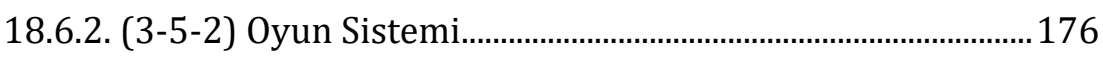

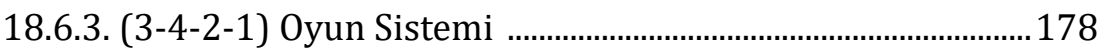

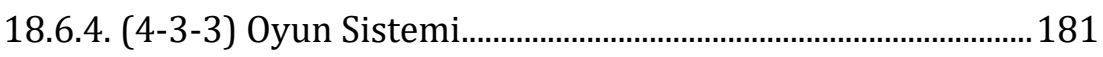

18.6.5. (4-4-2) Oyun Sistemi...................................................................183

18.6.6. (4-4-2) Oyun Sistemi............................................................... 183

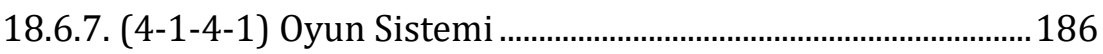

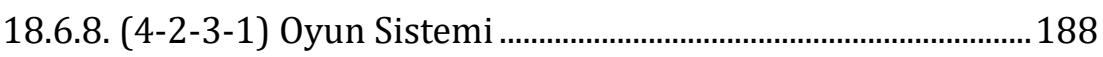

Modern Oyun Sistemlerine Toplu Bir Bakış ........................................191

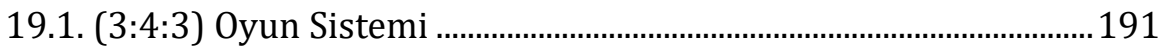

19.1.8. Modern Oyun Sistemlerinin Özellikleri .................................. 198

19.1.8.1. Alana Hakim Olma (Alan Kazanmak) ................................. 198

19.1.8.2. Gol Atma Şansının Yaratılması.............................................199

19.1.8.3. Kaleye İsabetli Şut Yerleri ve Şekilleri................................199

19.1.8.4. Başarı Faktörlerinde Sistemin Esnekliği.......................................201 


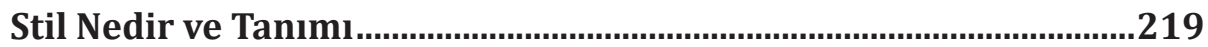

Günümüzde Oyun Anlayıșı ve Taktiğe Olan Etkileri ............................221

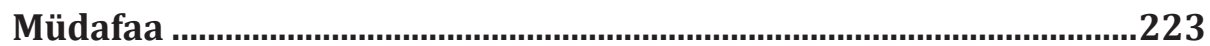

22.1. Müdafaa Oyununun Temel Şekilleri...................................................223

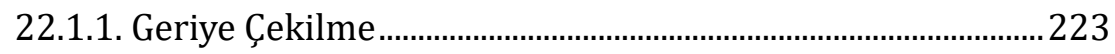

22.1.2. Forechecking (Önde Baskl) .......................................................223

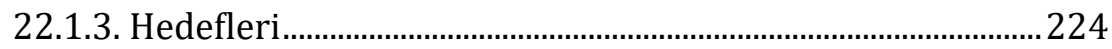

22.1.4. Hangi Şartlarda Yapılması Daha Uygundur............................2224

22.1.5. Forechecking Oynayan Takıma Karşı Alınabilecek Önlemler. 224

22.1.6. Forechecking Tekniğini Uygulama Seçenekleri.....................224

22.1.7. Forechecking de Müdafaa Oyunu Organizasyonu Koşulları...225

22.1.8. Forechecking de Kuvvetli Bir Müdafaa Organizasyonu......226

22.2. Forechecking de Müdafaa Oyununun İmkanları ..............................227

Ofsayt Tuzağı ve Kurtulma Yolları.........................................................229

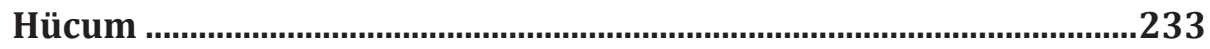

24.1. İyi Bir Hücumun Özellikleri.................................................................233

24.1.1. Hücum Çeşitleri.......................................................................233

24.1.2. Karşıdan Hücum .......................................................................233

24.1.3. Karşıdan Yapılan Hücumun Koşulları.......................................233

24.2. Kontratak (Hızlı Hücum) …………………………………………....234

24.2.1. Kontratak İçin Koşullar ve Amaçlar........................................234

24.2.2. Kanattan Kontratak Çalışmaları...............................................235

Hücum Organizasyonu İçin Gerekli Temel Koşullar ............................257

25.1. Hücum Olanakları Kanatlardan Oyun..............................................257

25.1.1. Kanatlardan Oyun Çalışmaları..............................................258

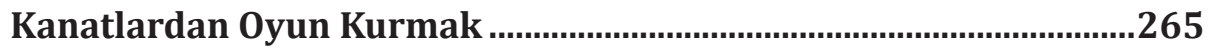

26.1. Oyun Formu ile Kanattan Oyun...…………………………………….... 283

Oyun Yönünü Değiştirmek ve Alıştırmaları.............................................299 
Duvar Pası ve Seçenekleri

28.1. Duvar Pasındaki Evreler

28.2. Hücumda Grup Taktik: Duvar Pası Dergi

28.3. Duvar Pasının Uygulanışı ve Belirleyici Özellik:

2:1 Oyunla Uygulanışı.

28.4. Duvar Pası Çalışmaları

Topu Pas Olarak Almak.

29.1. Takım Arkadaşının Arkasından Bindirmek.

29.2. Kuvvetlendirilmiş Müdafaaya Karşı Taktiksel Oyun Davranışları.. 352

29.3. Bir Oyunun Dış Koşulları ve Taktiğe Olan Etkileri.

30.1. Topa Sahip Olmak ve Destek ile İlgili Çalışmalar 355

30.2. Derinlik ve Derinlikle İlgili Çalışmalar 358

30.3.1. Derinliğine Oyun Kurma.

30.4. Geciktirme (Oyalama) ve Geciktirme ile İlgili Çalışmalar. 370

30.5. Birikme ve Birikme ile İlgili Çalışmaları

30.6. Denge ve Denge ile İlgili Çalışmalar.

30.6.1. Kademe-Kontrol ve Topun Pozisyonuna Göre Kayma Çalışmaları

30.7. Müdafaa Oyununda Beş Prensip

Hücum Prensiplerine Karşı Alınacak Müdafaa Önlemleri

32.1. Topa Sahip Olmak ve Destek Çalışmaları 389

32.2. Yaratıcılık (Şahsi Teşebbüs) ve Çalışmaları 393

32.3. Derin Pas ve Sızma Çalışmaları 395

32.4. Genişlik ve Çalışmaları 399

32.5. Hareketlilik ve Çalışmaları 405

32.6. Derinlik ve Çalışmaları 407

Pres Nedir Nasıl Yapılır. .423

33.1. Hangi Tür Presler Vardır 424

33.1.1. Hücum Presi. 425

33.1.2. Orta Saha Presi 430 
33.1.3. Müdafaa Presi............................................................................ 440

33.1.4. Pres Eğitimi ile İlgili Alıștırma ve Antrenman Formları .... 442

33.1.5. Hücum Presine Karşı Oyun Kurma ............................................. 458

33.1.6. Müdafaaya Yönelik Pres................................................................. 463

Serbest Vuruşlar .................................................................................477

34.1. Taç Atma Tekniği ve Çalışmaları........................................................... 479

Köşe Vuruşu (Korner) .....................................................................................491

35.4. Serbest Vuruş Çalışmaları ....................................................................... 512

İç Sahada ve Deplasmanda Oynanan Maçlarda Uygulanan

Farklı Taktikler..................................................................................531

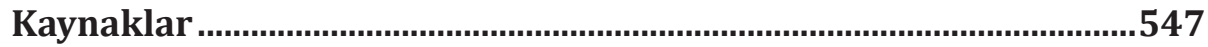

Özgeçmiş...........................................................................................551 


\section{KAYNAKLAR}

1. Albeck,T.,Kegel,S.,Fussballtraining,Das Schnelle Umschaltspiel der "roten Bullen", Zeitschrift für Trainer, Sportlehrer und schiedsrichter, Philippka Verlag,Münster,S.18-19,2014/8

2. Auste, N., Konditionstraining Fussball, rororo, 1987.

3. Bailey, İ,C.,Teller,L,F., Soccer, Sounders Physical Activities Series, 1970.

4. Bauer, G., Fussball Perfekt vom anfanger zum Profi, dritte völlig neubearbeittete auflage, BLV Verlagsgesellschaft,München,Bern,Wien, 1976.

5. Bauer, G., Lehrbuch Fussball,Erfolgreiches Training von Technik-Taktik und Kondition, BLV Verleggesellschaft,München, 1990.

6. Bauer, G., Richtig Fussballspielen, blv sportpraxis, BLV Verlagsgesellschaft, München,1983.

7. Benedek, E., Zweikampfe im Fussball, Verlag Bartels \& Wernitz, 1. Auflage, Berlin, 1983.

8. Benedek,E., Fussballtraining mit Kindern, Bartel \& Wernitz Sportverlag, 1. Auflage, Berlin, 1987.

9. Bisanz, G., Fussballtraining, Zeitschrift für Trainer, Sportlehrer und schiedsrichter, Philippka Verlag,Münster.

10. Bisanz,G., Fussball-Lehrplan 3,Jugenttraining Aufbau und Leistung, BLV Verlagsgesellschaft, München,1987.

11. Bisanz,G.,Gerisch,G., Fussball, Training, Technik, Taktik, Sachbuch rororo, Juni, 1981.

12. Bisaz,G., Gerisch, G., Fussball, rororo,1988.

13. Bookmann,j., Fussballtraining, Den ball sichern und behaupten ,Zeitschrift für Trainer, Sportlehrer und schiedsrichter, Philippka Verlag,Münster.,S.23, 2010.

14. Bookmann,J., Fussballtraining,klug verteidigen, Zeitschrift für Trainer, Sportlehrer und schiedsrichter, Philippka Verlag,Münster, S.38-40,2011/4.

15. Brüggemann,A., Modernes Fussballtraining, Schorndorf, 1982.

16. Burger,T., Fussballtraining, Zeitschrift für Trainer, Sportlehrer und schiedsrichter, Philippka Verlag,Münster,S.13-15,2014/8

17. Czerwionka,T.,König,S., Zeitschrift für Trainer, Sportlehrer und schiedsrichter, Philippka Verlag,Münster, Jahresplanung:Warum nicht wie die Stutzpunkte trainieren,Teil 8:Drei Einheiten Gruppentaktischen Angriffmöglichkeiten. S.40 2015/4

18. Daniel, J., Hamsen,G., Fussball Jugend Training,Grundlagen-Übungen-Programme, Hamburg, Marz, 1990. 
19. DFB-Talentförderprogramm,İnfo-Abende Für Vereinstrainer,Training Des 1:1 in Der Defensive,S.7,Oktober,2006.

20. DFB Talentförderung programm Anbieten und Freilaufen

21. DFB-Talentförderprogramm,İnfo-Abende Für Vereinstrainer,Training Des Verteidigens zu zweit,S.8,April,2006.

22. Elgert, N., Schreiner, P., Angrifffussball, Teil 2, Kombinationsspiel,Spiel in die Tiefe, Torschuss, 1. Auflage, Marz, 2005.

23. Elgert, N., Schreiner, P., Die Kunst des Angrifffussball, Teil 1, direkt Spielen, blitzschnell kombinieren, erfolgreich angreifen, 1. Auflage, November, 2004.

24. Falopa,M., Concacaf Tecnical Director Fifa İnstructor,The Brazilian Way,To Play Soccer,2nd Edition;1st Edition publisihed in Trinidad and Tobago, Sao Paulo, Brazil, 1997.

25. Feldkamp,M.,Fussballtraining,Aus Zweikampfen Dreikampfe machen, Zeitschrift für Trainer, Sportlehrer und schiedsrichter, Philippka Verlag,Münster, S.7,2015/1+2.

26. Frank, G., Konditions-Gymnastik Für Das Fussballtraining,1. Auflage, Bartels \& Wernitz Sportverlag, Berlin 1987.

27. Fuhrmann,R., Fussballtraining,Breitseite Nutzen, Zeitschrift für Trainer, Sportlehrer und schiedsrichter, Philippka Verlag,Münster,S.10,2012/8.

28. Fussballtraining, Zeitschrift für Trainer, Sportlehrer und schiedsrichter, Philippka Verlag,Münster,S.4, 2012/3.

29. Fussballtraining, Zeitschrift für Trainer, Sportlehrer und schiedsrichter, Philippka Verlag,Münster,S.4, 2012/9.

30. Fussballtraining, Zeitschrift für Trainer, Sportlehrer und schiedsrichter, Philippka Verlag,Münster,S.12, 2012/12.

31. Fussballtraining, Zeitschrift für Trainer, Sportlehrer und schiedsrichter, Philippka Verlag,Münster, S.12, 2012/9.

32. Fussballtraining, Zeitschrift für Trainer, Sportlehrer und schiedsrichter, Philippka Verlag,Münster, S.3, 2011/4.

33. Grosser, N., Starischka, S, Zimmermann,E., Konditions Training, 1981.

34. Grosser,M., Brüggemann,P., Leistungssteuerung in Training und Wettkampf, blv sportwissenschaft ,München, 1986.

35. Hamsen,H, K., Fussball Funktions Gymnastik,Dehnen-Kraftigen-Entspannen, Sport rororo, Hamburg,Dezember,1988.

36. Heddergott,H- K., Neue Fussball-Lehre, 4. Erweiterte Auflage,by Limpert-Verlag GmbH,Bad Homburg v. d. H. Umschlagentwurf, Wurf Weis,Frankfurt am Main, 1976.

37. Hübscher, S., Erfolgreiches Flügelspiel im Fussball, İnstitut für jugendfussball, 2006.

38. Klante, R., Praktische TrainingsLehre, Algemeine und Spezielle konditions im Fussballsport, Bayerischer Fussball-Verband.

39. Klante,R., Der Weg zur B-Lizens, Bayerischer Fussball-Verband, 1987.

40. Klante,R., Die Periodisierung des Fussballtraining, Bad Homborg, 1979.

41. Krempel, J., Konditionstraining,Training-Technik-Taktik, Sport rororo, Hamburg,September,1987.

42. Kunze,A., Fussball, Sportverlag, Berlin, 1981.

43. Lammich, G., Kadow, H., Spiele Für das Fussballtraining, Sportverlag Berlin,1982.

44. Marotzke, H.,Hotz,A., Ebesberger,H., Spring,R., Kern,W., Furrer,G., The FIFA/Coca-Cola World Football Youth Academy, Zurich Switzerland,1987. 
45. Martin, D., Grundllagen der Trainingslehre,Teil 1, Schorndorf,1977.

46. Martin, D., Grundllagen der Trainingslehre,Teil 2, Schorndorf,1977.

47. Matarazzo,P.,Fussballtraning, Zeitschrift für Trainer, Sportlehrer und schiedsrichter, Philippka Verlag,Münster,S.14-15,2014/8.

48. Mayer,R., Torschuss Training Fussball, rororo Sport, Hamburg,Marz, 2001.

49. Palfai,J., Moderne Trainingsmethoden im Fussball, auflage,bartels \& Wernitz, 1976.

50. Peter,B., Rangring,R.,Führungprenzipien,Teambulding,Atletik und Angriffsfussball, Zeitschrift für Trainer, Sportlehrer und schiedsrichter, Philippka Verlag,Münster

51. Peter,R., Fussball von Morgen, Modernes Verteidigen, Stellenwert, Methodik und Strategie des ballorientierten Abwehrspiels, Deutscher Fussball-Bund, 2.korrigierte Auflage, Band 4 der reihe philippka-Sportverlag, Münster,2007.

52. Peter,R.,İndividuelle Technisch-Taktisch Details im Spielaufbau, İnternational Trainer-Kongress,S.76-81,Bremen,2013.

53. Punga,M., Trainen van jonge voetballers, Eerste druk, by Acco (Academische Coöperatieve Vennootschap crba) Leuven (Belgie),2001.

54. Rangrink,R.,Schnelles Umschaltspiel-von Abwehr auf Angriff und von Angriff auf Abwehr,İnternational Trainer-Kongress,S.12. 19,Bremen,2013.

55. Reer,M.,Fussballtraining, Zeitschrift für Trainer, Sportlehrer und schiedsrichter, Philippka Verlag,Münster, S.14, 2012/6+7.

56. Reimöller,D., Voggenreiter,T., Erfolgreiches Angreifen,Moderne Spielsysteme-vom Spielaufbau bis zum Torerfolg, Zweite überarbeitete Auflage, DFV Der Fussballverlag, 2008.

57. Röper,A.,Fussballtraining,Aus Engen Raumen, Zeitschrift für Trainer, Sportlehrer und schiedsrichter, Philippka Verlag,Münster,S.9,2012/10.

58. Röthing, G., Sportwissenschaftliches Lexion,5. Auflage, Schorndorf, 1983.

59. Röthing, G., Trainingslehre, Bad Homburg, 1979.

60. Ruttensteiner,W.,Fussballtraining, Zeitschrift für Trainer, Sportlehrer und schiedsrichter, Philippka Verlag,Münster, S.32-33,2013/12.

61. Scherb,M., ÖFB Trainerseminar:Praxisbeispiel Spiel Über Breite,Spieler Pas in die Tiefe

62. Schreiner, P., Erfolgreich Dribbeln,Grundlagentraining Fussball, rororo Sport, Hamburg Juni, 1999.

63. Schreiner, P., Fussball Perfekte Ballbeherrschung, Meyer Verlag, Aachen, 2009.

64. Schreiner, P., Tomaz, C., Koordinatives Technik- und Taktiktraining im Fussball,

65. Talaga, J., Fussballtaktik, Sportverlag, Berlin, 1979.

66. Talaga, J., Fussballtechnik, Sportverlag, Berlin, 1979.

67. Talaga, J., Fussballtraining, Sportverlag, Berlin, 1979.

68. Ueberle, H., Schmidt, R, H., Fussball-Lehrplan 1,Fussball-Training mit der Nationalmannschaft, BLV Verlagsgesellschaft, Deutscher Fussball-Bund, München, 1982.

69. Ueberle, H.,Trainingsbuch für Fussballtrainer, BLV Verlagsgeselschaft,München,1982.

70. Verheijen, R., Handbuch Fussballkondition, Amsterdam, 1997.

71. Verlag,Münster,S.16,2008/11.

72. Weineck, J., Çeviri Tanju Bağırgan, Futbolda Kondisyon Antrenmanı, Spor Yayınevi ve Kitapevi, Ankara, 2011.

73. Weineck, J., Erlangen., Teil 1. Das Konditionstraining des Fussballspilers,Beitrage zur Sportmedizin,Band.43, 1992. 